\title{
Hysteresis in Perovskite Solar Cells
}

\section{Outline:}

1. Introduction.

2. Origin of Hysteresis

2.1 Ferroelectric

2.2 Charge Trapping/Detrapping

2.3 Ion Migration

2.3.1 Migrating Defect/Ion Species

2.3.2 Detailed Migration Process/Channel

2.3.3 Activation Energy Characterization

2.3.4 Capacitive studies

2.3.5 Energy Band Bending or Internal Field Screening

3. Suppression of Hysteresis

3.1 Large Crystal Size

3.2 Presence of PCBM Molecules

4. Application in Devices

4.1 Photovoltaic Devices

4.2 Hysteretic Switching Application

5. Conclusion 


\begin{abstract}
Inorganic-organic halide organometal perovskite, e.g. $\mathrm{CH}_{3} \mathrm{NH}_{3} \mathrm{PbI}_{3}$ and $\mathrm{CsPbI}_{3}$, etc, is a dramatically rising star in the photovoltaic area since 2009 , due to its exceptionally high power conversion efficiency (PCE) and simple fabrication process. Despite its relatively short history, intensive investigation is concentrating on this material, ranging from crystal structure and photophysical characterization, to performance optimization and device integration. Yet, applied in photovoltaic devices, this material is suffering from hysteresis, that is, the difference of $J-V$ curve during the sweeping in two directions (from short-circuit towards open-circuit and vice versa). This abnormal behavior significantly influences the potential large-scale application. This review will concentrate on the recent theoretical and experimental efforts to reveal the origin and mechanism of hysteresis. The proposed origins include (1) ferroelectric polarization (2) charge trapping/detrapping (3) ion migration. Currently more and more evidences consistently support that ion migration plays the key role on the hysteretic behavior in perovskite solar cells. Hence, we will summarize the recent results on ion migration, such as the role of grain boundaries (GB) on ion migration, activation energies measurements, capacitive characterization and internal electrical field modulation, etc. In addition, we also review the devices with alleviation/elimination of hysteresis, which involve either large crystal sizes or PCBM molecules. In the following part, during practical application, we have to mention that devices with hysteresis still obtain promising PCE. Furthermore, the hysteretic property has been utilized in memristive switching devices. In sum, the Review emphasizes that organometal halide perovskites, in which strong coupling between ionic migration and free charge carriers transport under external photo/electrical field, have to be carefully treated for the mobile defects/ions inside, which can be modulated by either crystalline structure or chemical passivation.
\end{abstract}




\section{Introduction:}

Being a rapidly rising star on the horizon of photovoltaic research area, organometal trihalide perovskite solar cells ( $\mathrm{PSCs}$ ), e.g. $\mathrm{CH}_{3} \mathrm{NH}_{3} \mathrm{PbI}_{3}\left(\mathrm{MAPbI}_{3}\right)$ and $\mathrm{CsPbI}_{3}$, have achieved surprisingly remarkable power conversion efficiencies (PCE) of up to $22.1 \%$ [1] in $<6$ years' intensive investigation. The unique electrical band structure of perovskite materials makes it as one of the promising candidates to replace or complement current silicon dominated photovoltaic market. (1) Direct bandgap leads to a higher light absorbance, comparing with the one of silicon [2]. (2) Tunability of bandgap ranges from $1.4 \mathrm{eV}$ to $2.3 \mathrm{eV}$ [2-4]. (3) High dispersion of conduction band (CB) and valance band (VB) gives rise to the long-range balanced electron and hole transport $[5,6]$, significantly suppressing the photogenerated charge recombination. (4) Excellent defect tolerance property enables low-cost solution-process manufactory, viz. spin-coating, inkjet printing, etc. [7-9].

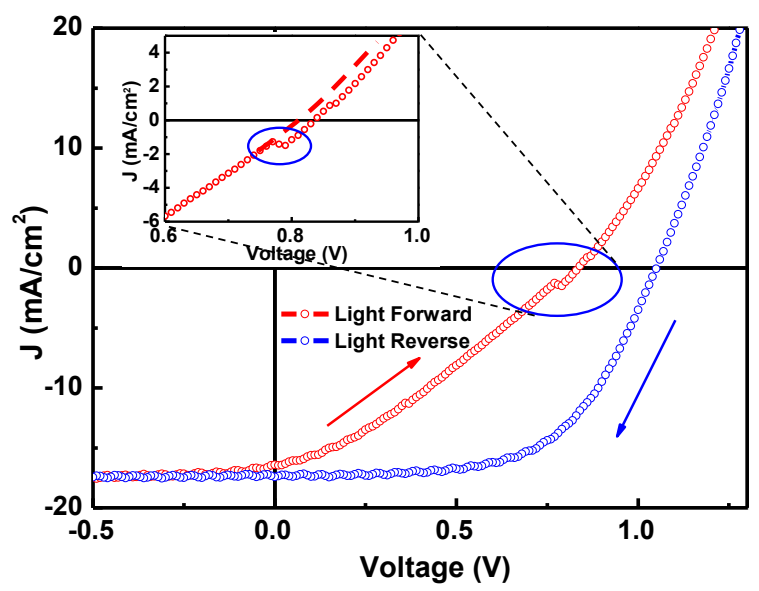

Figure 1. A typical J-V curve hysteresis behavior in a typical perovskite solar cell, with scanning speed of $\sim 0.9 \mathrm{~V} / \mathrm{s}$. The arrows exhibit the directions of voltage scanning. Inset indicates the kink in the $J-V$ curve. The dashed red line is the extension of the $\mathrm{J}-\mathrm{V}$ curve below $\sim 0.75 \mathrm{~V}$ based on standard single junction diode equation, and the blue circle indicates the horizon shift of the curves near the flat-band condition. Reprinted with permissions from [10]. Copyright $(2016$ by John Wiley \& Sons, Inc.

Accompanying with such outstanding properties and astonishing development of PCE, 
however, anomalous hysteretic current-voltage (I-V) characteristic in PSCs, as shown in

Figure 1 , is still one of the "clouds" obscuring its pathway to their large-scale commercial application. Hysteretic $I-V$ characteristic, or short for hysteresis in this Review, is the photocurrent responses of the PSCs demonstrate the discrepancy of $I-V$ curve between two sweeping directions.

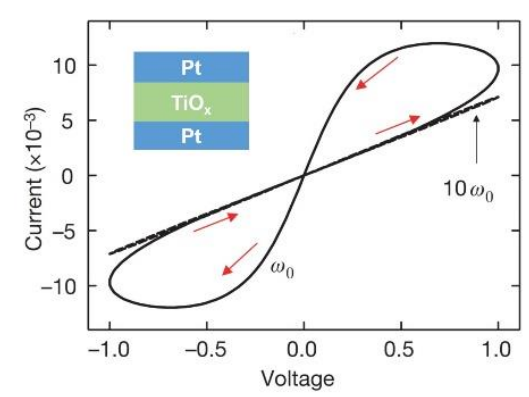

Figure 2. A typical hysteresis in $\mathrm{J}-\mathrm{V}$ curve characteristic of a $\mathrm{Pt} / \mathrm{TiO}_{\mathrm{x}} / \mathrm{Pt}$ device. Insets is the schematic diagram of a memristive device based on $\mathrm{Ag} / \mathrm{TiO}_{2} / \mathrm{Ag}$ structure. Adapted with permissions from [11]. Copyright $\mathrm{C} 2008$ Nature Publishing Group.

In history, this unconventional property has become acquainted in various dissipative devices and systems [12]. As shown in Figure 2, a simple $\mathrm{Pt} / \mathrm{TiO}_{\mathrm{x}} / \mathrm{Pt}$ two-terminal device [11] exhibits a rich hysteretic $I-V$ characteristics. When the scanning frequency increases by 10 folders (i.e. $10 \omega_{0}$ ), the hysteresis loop collapses. Human memory system [13], i.e. synapse based neural networks, for instance, is also related to such a mechanism.

Hysteretic behavior is generally observed in the systems with special "inertia" [12], in which there is a delay between the change of the properties and the external stimulation (electrical or optical field). This temporal-dependent behavior can be described as a 
"memory" effect, meaning that present properties are determined by past conditions or their history. There are three possible mechanisms responsible for this historydependence resistance switching behavior in devices [14], i.e (i) formation/rupture of highly conductive filaments, (ii) accumulation of mobile ions or defects, (iii) phase transition, etc. In detail, (i) inevitable defects exists in bulk, such as vacancies or interstitial defects, can be driven by external electrical field towards the opposite electrodes, forming conducting filaments. Hence, formation and rupture of these conducting pathways lead to low and high resistance states, respectively, shown in Figure 3 (a). (ii) Rather than forming conducting filament, in this model, ions accumulated at the semiconductor/metal interfaces results in the modulation of local interfacial barrier for the charge injection/extraction, shown in Figure 3(b). (iii) As illustrated in Figure 3(c), the bulk material between two electrodes undergoes phase transition (i.e. conducting crystalline and insulating amorphous phases) due to electrical current induced heating.

(a)

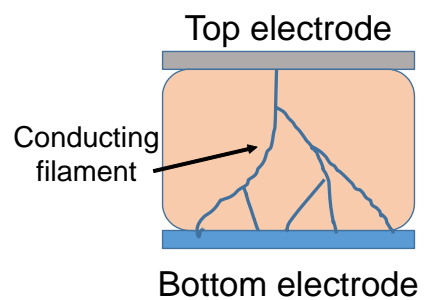

Filament (b)

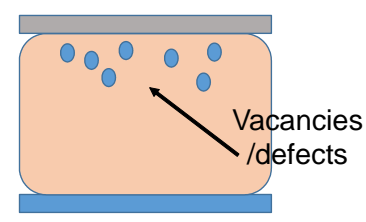

Mobile ions (c)

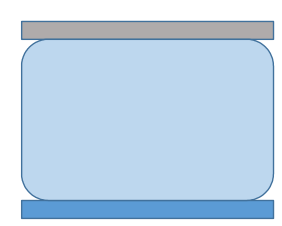

Phase transition

Figure 3. Schematic diagrams of different mechanism of resistive switching ( $J-V$ curve hysteresis). (a) Formation and rupture of conducting filaments. (b) Modulation of interfacial barrier induced by the concentration of ions. (c) Conducting/insulting phase transition. Reprinted with permissions from [14]. Copyright@2008 Elsevier Ltd.

In this Review, we specifically aim to discuss the hysteresis phenomena in organometal 
trihalide PSCs, and the origin of this abnormal behavior. First, we will briefly summarize the observation of this hysteretic behavior. Next, we will focus on examining microscopical physical models, including ferroelectric switching, charge trapping/detrapping, and ion migration. Third, we will present the approaches to suppress hysteresis and the potential applications of this behavior in devices.

Snaith et al [15] have provided a comprehensive summary on the features: (1) hysteresis is dominantly associated with the perovskite material itself. (2) Contact materials, i.e hole and electron transport layers (TLs), are playing critical roles in this behavior, including the selection and the morphology (mesoporous or planar) of the TLs. (3) The time scale of hysteresis is $\sim 100 \mathrm{sec}[16,17]$, which exhibits a contrast for the typical charge generation/recombination process ( n ns) in PSC [5]. (4) The hysteresis strongly depends on the external scanning parameters [18], such as scanning rate, amplitude of external electrical field, scanning direction, pre-scanning conditions, etc. Hence, based on the above general observation, we will discuss mechanisms in detail.

\section{Origin of Hysteresis}

\subsection{Ferroelectricity}

Ferroelectricity is a property possessed by a class of materials, in which the spontaneous polarization, $P$, can be modulated by an external electrical field. The polarization originates from non-centrosymmetric structures. Although $\mathrm{MAPbI}_{3}$, a typical perovskite material for instance, belongs to the centrosymmetric tetragonal space group 
$[2,19]$ of $I 4 / \mathrm{mcm}$ at room temperature, the rotation and reorientation of the MA group [20] within the $\mathrm{PbI}_{6}$ cages can decrease the crystal lattice symmetry, resulting in the spontaneous polarization $[21,22]$. The polarization of organometal perovskite materials has been proved by both theoretically and experimentally. Employing density functional theory (DFT), Frost et al [23] and Rappe et al [24,25] reported the appearance of a strong dipole moment or polarization in the bulk of perovskite materials. X-ray diffraction (XRD) has shown a lower symmetry structure at room temperature [26] and Raman spectra confirm the intrinsic MA vibrational mode which gives rise to the intrinsic dipole inside [27]. In addition, electroabsorption spectroscopy, or Stark spectroscopy [28], provides the unambiguous evidence of a permanent dipole in the organolead halide perovskite [10,29].

Two criteria, (1) the existence of polarization and (2) the polarization can be switched by an external electrical field would need to be met. For the second criterion, several groups, such as Chen et al [30], Coll et al [31] and Kutes et al. [32], have clearly demonstrated the switching of spontaneous polarization, that is, piezoresponse hysteresis loop in both amplitude and phase, by using piezoelectric force microscopy (PFM), shown in Figure 4. Wei et al [26] have also demonstrated the ferroelectric property employing traditional $E-P$ measurement, on the basis of classical SawyerTower circuit. 


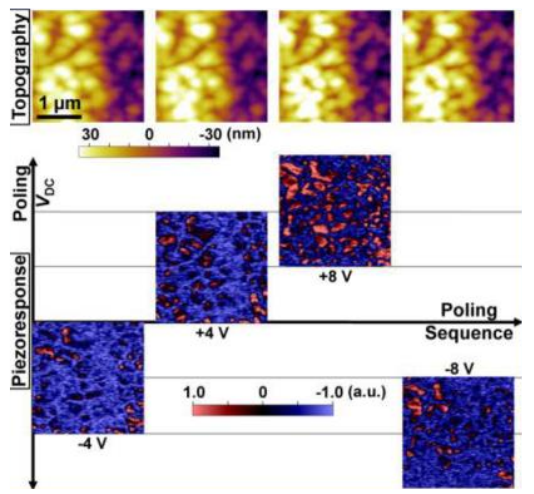

Figure 4. Images at top row are the topography of perovskite films, images at second line are the PFM image after DC bias, indicating the change of ferroelectric domain after biasing process. Reprinted with permissions from [32]. CopyrightC2014 American Chemical Society.

Based on the existence of ferroelectricity, there are models established to explain the hysteresis behavior in the perovskite materials. When applying an electrical field, as shown in Figure 5, these dipoles, due to the MA group rotation or distortion of inorganic frame, are aligned following the direction of the external field. This dipole alignment process generates a compensated field, i.e. depolarization field. This process significantly influences the effective potential dropped in the bulk and increases/decreases the separation of charge carriers. In a first-order approximation, we obtain:

$\mathrm{V}_{\mathrm{oc}+}=\mathrm{V}_{\mathrm{BI}}+\mathrm{V}_{\mathrm{p}}$

$\mathrm{V}_{\mathrm{oc}-}=\mathrm{V}_{\mathrm{BI}}-\mathrm{V}_{\mathrm{p}}$

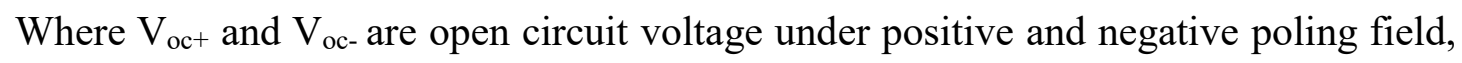
respectively. $\mathrm{V}_{\mathrm{BI}}$ is the built-in potential in the device, ascribed from the work function difference between two selective electrodes. $V_{p}$ arises from the depolarization field due to the dipole alignment. This change of $\mathrm{V}_{\mathrm{oc}}$ is consistent with the observation of shift of $V_{o c}$ during the J-V curve measurements, as shown in Figure 1. 
In addition, the change of the prevalent internal field also gives rise to the change of band bending, influencing the local interfacial barriers and space charge, as shown in Figure 5. In the ferroelectric perovskite with multidomain structure charge carriers move along the domain boundary. This is noted as a "ferroelectric highway" as proposed by Frost et al $[23,33]$. This modulation of the internal electrical field, thus, results in the hysteresis of the $J-V$ measurement, which reflects the effective extraction of photogenerated charge carriers through TLs [34].
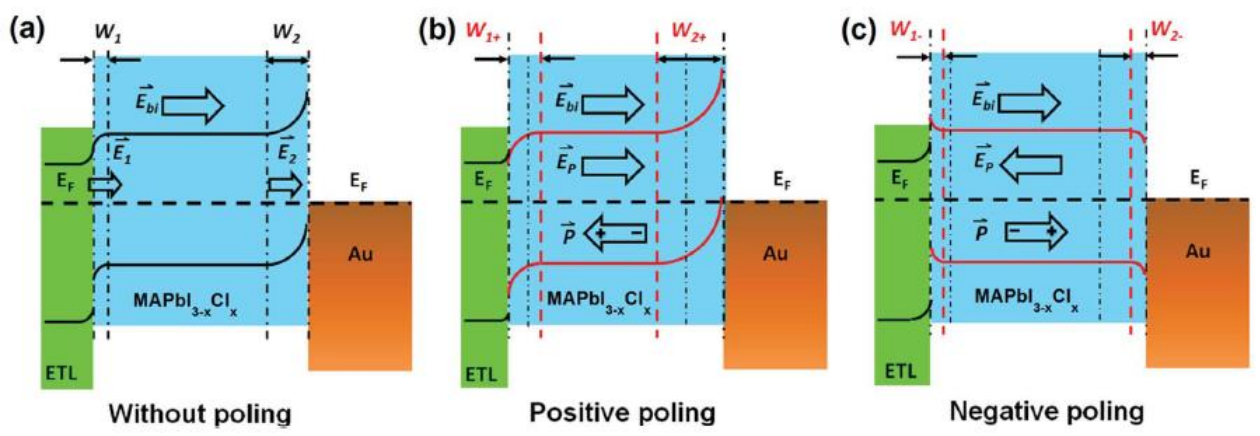

Figure 5. Schematic band diagram of influence of ferroelectric polarization on the internal field. (a) Without poling effect on the perovskite. (b) poling field opposite the built-in field. (c) poling field follow the same direction of builtin field. Reprinted with permissions from [30]. Copyright $\subset 2015$ Royal Society of Chemistry.

Although the ferroelectricity model for the explanation of hysteresis gained some acceptance, it is still suffering from several arguments. (1) It is still controversial to identify the existence of ferroelectric property in organometal perovskite. Coll et al [32] has obtained the switching behavior of polarization, however, the field decay is very fast. By exploiting Sawyer-Tower circuit to characterize the polarization, there is no standard $P-E$ hysteresis loop. Moreover, both Xiao et al [35] and Fan et al [36] claim that there is no obvious phase contrast during the positive and negative poling process 
in PFM characterization. Wei et al [26] have obtained some features of ferroelectricity, i.e "s" shape during the $P-E$ measurement. However, the ferroelectric effect is too small to be convincing.

(2) Time scale of polarization switching does not agree with the one observed in $I-V$ curve hysteresis. Based on first principle simulation (e.g. DFT), the time interval for the polarization switching is $\sim$ ns region [37]. Leguy et al [35]estimate the time interval is within ms region. While the typical switching observed in PSC is $>10 \mathrm{sec}$, as summarized before.

(3) Ferroelectric materials require an electrical field larger than the coercive field inside. This contradicts with the observation of step-wise $J-V$ curve measurements which alsways exhibit a transition-like behavior [38]. Hence, although the contribution of ferroelectricity for the hysteresis is still under debate, the above discussion reveals that ferroelectric polarization may not play the dominating role in the $J-V$ hysteresic behavior.

\subsection{Charge Trapping/Detrapping}

Low-temperature and solution processing of perovskite film inevitably involves a certain amount of defect states inside, which show potentially impact on the charge separation/recombination and charge transport [39]. These defects inside can be categorized into two categories: (1) defects located at the CB/VB band edge following exponential decrease distribution and (2) defects at the deep-level in the bandgap with 
Gaussian distribution [40]. For the first ones, evidences consistently illustrate that energetic width of the defect states near the band edge, i.e. Urbach energy, is between $20 \mathrm{meV}$ and $40 \mathrm{meV}$, depending on the fabrication methods [41]. This value is much smaller than in many typical semiconductor materials, demonstrating promising performances comparable with classical inorganic solar cells [42]. For the second ones, however, these defects reside deep within in the bandgap and serve as trap sites for the charge carriers under working conditions, playing important roles in the ShockleyRead-Hall non-radiative recombination [43]. According to the classical detailed balance model [44], any non-radiative recombination in the open circuit condition leads to the loss of PCE [45]. By filling and releasing charges at these trap sites under an electrical field, the photogenerated charge transport is modulated and the performance of devices, therefore, exhibits the hysteretic behavior.

Atomistic simulations, as summarized in Figure 6, reveal the energetical distribution of possible defects states, viz. vacancies, antisite and interstitial ones [46]. With the help of spectroscopic characterization, it is evident that the traps are dominantly accumulated at the interface or surface, where the periodical crystalline structure is not guaranteed or due to strong electron-phonon coupling [47-49]. Temperature-dependent admittance spectroscopy enables us to further identify the energetic distribution of these defects in the bandgap [50,51]. It is found that deep-level defects, which are responsible for non-radiative recombination, requires higher formation energy [52]. This explains the origin of the excellent defect tolerance of these perovskite materials. 

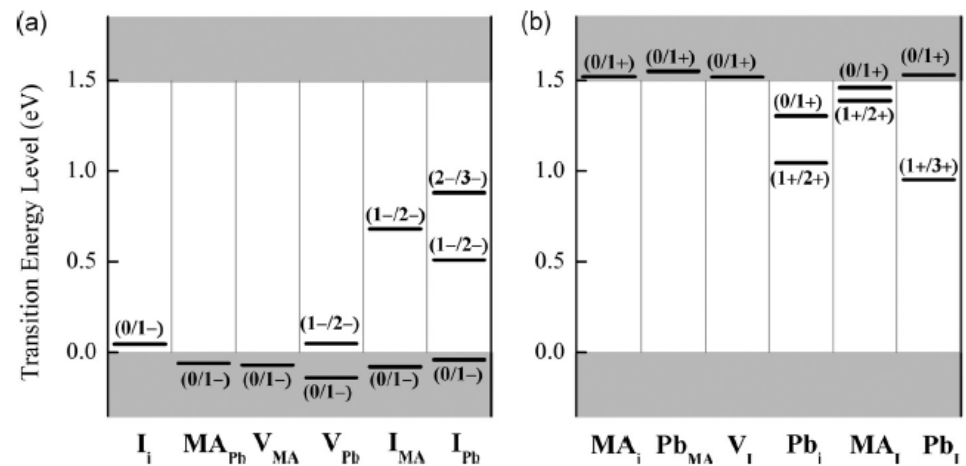

Figure 6. Energetically distribution of defect states in the bandgap of perovskite semiconductors, including vacancies, interstitial and antisite defects. Reprinted with permissions from [52]. Copyright@2014 AIP Publishing LLC.

Taking account of these defect states, it is natural to compensate or fill them using different chemical methods [53-56] or passivation processes. It has been also widely observed that the involvement of phenyl-C61-butyric acid methyl ester (PCBM) molecules, either by mixing as bulk heterojunction [57,58] or inserting a single layer [51] into devices, is able to significantly alleviate or eliminate the hysteresis. Wojciechowski et al [59] provide spectroscopic evidence that the C60 buckyballs form self-assembled monolayers and passivate or inhabit the traps state at the interface between $\mathrm{TiO}_{2}$ and perovskite layer. The observed significantly reduced hysteresis is originated from the passivation at this interfaces. Furthermore, Xing et al [60] observe an obvious reduction of perovskite/ $\mathrm{TiO}_{2}$ interfacial barrier by inserting a PCBM layer on the $\mathrm{TiO}_{2}$. This PCBM layer passivates the perovskite surface states acted as recombination centers adding extraction barriers for the photogenerated charge carriers as illustrated in Figure 7. Shao et al. [51] attributed the elimination of hysteresis to the passivation of charge trap states in the bulk of perovskite film during the thermal annealing process. Thermodynamically activated PCBM molecules diffuse into the 
bulk of perovskite, passivating traps at surface and grain boundary (GB), thus enhancing the charge transport and charge extraction.

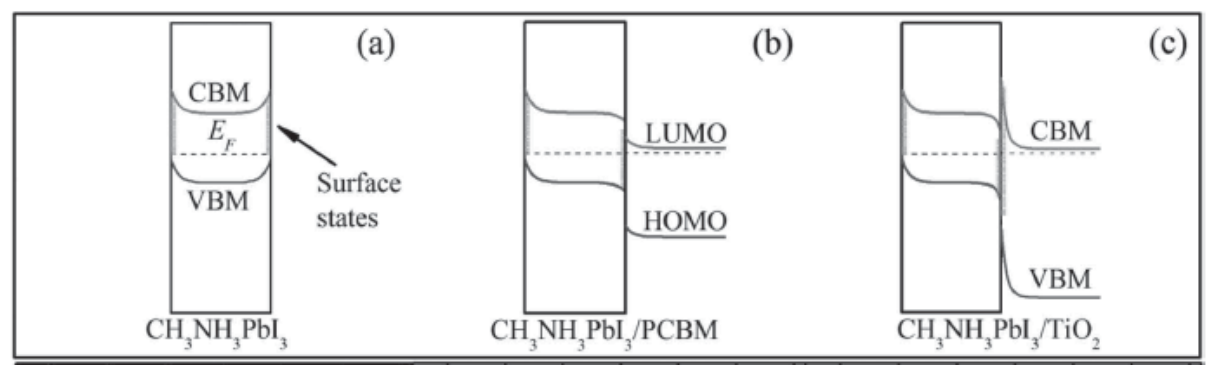

Figure 7. Schematic energy diagram of (a) pure perovskite material (b) interface perovskite/PCBM layer and (c) perovskite $/ \mathrm{TiO}_{2}$ layer. Reprinted with permissions from [60]. Copyright@2016 by John Wiley \& Sons, Inc.

Kelvin probe force microscopy (KPFM) [61,62], as a powerful tool to investigate the charge distribution, provides direct evidences of charge trapping and detrapping process. As shown in Figure 8, mapping the charge carrier density distribution across the cross section of the device, allows us to track the temporal evolution of accumulated charges after illumination. It has been observed that the accumulation of holes at the interface between perovskite and HTL materials after turning on the light, results in the reduction of the effective charge extraction through this interface. This observation of charge accumulation and unbalanced charge transport agrees with the studies conducted by electron beam-induced current (EBIC) measurements $[63,64]$. 


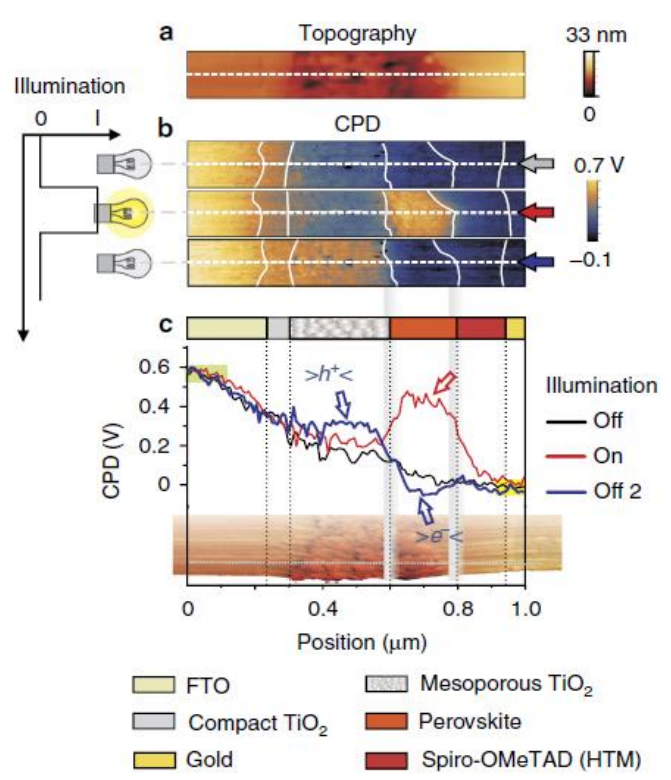

Figure 8 SKPM characterization of perovskite materials, with and without light illumination. The red line in the ON states indicates the accumulation of holes during the illumination condition. Reprinted with permissions from [62]. Copyright(C2014 Nature Publishing Group.

Although the passivation process significantly enhances the performance and decreases the hysteresis, it is found that the time interval for charge trapping and detrapping ranges within milliseconds [65], or even nanoseconds [66], which is much shorter than the typical time for the hysteretic behavior [67]. In addition, the observed giant switchable photovoltaic and slow (second range) increase in photocurrent after poling cannot be explained by charge trapping mechanism alone [35]. Therefore, Van Reenen et al. [65] recently proposed that, rather than a single origin, the hysteresis has to be understood in terms of combined factors, including both the ionic migration, which will be discussed in detail in following part and charge trapping/detrapping effect.

\subsection{Ion Migration}

As mentioned above, although there are several models proposed, concerning the time scale and further direct/indirect evidences (e.g. activation energy, band bending, etc), 
ionic migration is considered as the dominate factor, associated with not only hysteresis [68] but also other unusual emission and capacity behaviors [69-73]. Briefly, as illustrated in Figure 9, under external electrical field, ions are driven towards the opposite interfaces (perovskite/ETL and perovskite/HTL, respectively). These accumulated ions result in both the change of internal field and the modulation of interfacial barriers, thus giving rise to the hysteretic behavior. In the following, aspects of ion migration, i.e. the species of ions, ion migration channel, capacitive studies, thermal activation energy as well as the influence on band bending will be discussed in detail.

\subsubsection{Migrating defect/ion species}

There are several potential candidates to be considered as the migrating species in

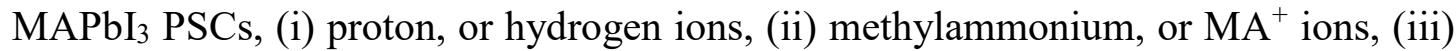
iodide ions $[74,75]$. In detail, these ions originated from defects states during lowtemperature fabrication, include vacancies (e.g. $\mathrm{V}_{\mathrm{MA}}, \mathrm{V}_{\mathrm{Pb}}$ and $\mathrm{V}_{\mathrm{I}}$ ) (i.e. Schottky defects), interstitials defects (e.g. $\mathrm{MA}_{\mathrm{i}}, \mathrm{Pb}_{\mathrm{i}}, \mathrm{I}_{\mathrm{i}}$ ) (i.e. Frenkel defects), antisite substitutions (e.g. $\left.\mathrm{MA}_{\mathrm{I}}, \mathrm{Pb}_{\mathrm{I}}\right)$, etc [76].

For (i) hydrogen ions, on the basis of first principle calculation (DFT method), Egger et al [77] propose that hydrogen ions formed through the displacement of iodide ions exhibit impact on observed mobile charged defects. Concerning $\mathrm{H}^{+}$ions, however, due to the weak acidity of methylammonium, it is difficult to maintain a high concentration 
of $\mathrm{H}^{+}$in PSCs [75]. Hence, even though there exists $\mathrm{H}^{+}$ions, they should play a minor role compared with other defects.

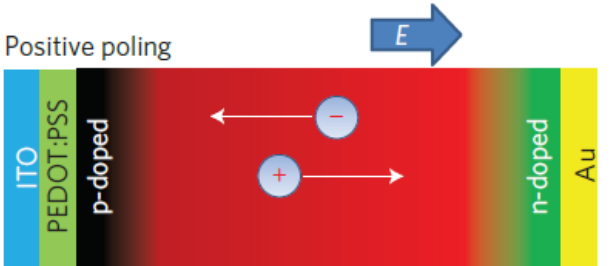

b

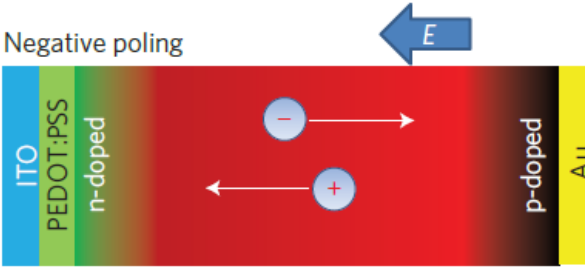

Figure 9. Schematic diagram of the ionic migration under external electrical field in a standard perovskite solar cells. Positive and negative ions drift towards to opposite electrodes and accumulate at these interfaces. Reprinted with permissions from [78]. Copyright $@ 2015$ Nature Publishing Group.

For the migration of (ii) MA ions, it is proposed as one of reasons for the phenomena of giant switchable photovoltaic in PSC [78]. Furthermore, employing the recently invented technique of photothermal induced resonance microscopy (PTIR), Yuan et al [79] observed the MA ion concentration contrast between before and after poling process. This redistribution of MA ions induced by external electrical field clearly indicates the migration of MA ions. Azpiroz et al [76] also proposed that, on the basis of computational studies, MA ions are driven by the external field to accumulate at the $\mathrm{TL} /$ perovskite interface or align by the field, thus hindering/enhancing the effective charge transport and extraction process.

However, concerning the extent of the contribution of MA on the hysteresis is still under debate. Van Reenen et al [65] estimate the diffusion coefficient of ions, which is responsible to the measured hysteresis, is around $10^{-11} \mathrm{~cm}^{2} / \mathrm{s}$. Eames et al [80] also obtain the similar order of magnitude, with diffusion coefficient of $10^{-12} \mathrm{~cm}^{2} / \mathrm{s}$. The estimated value for MA is $10^{-16} \mathrm{~cm}^{2} / \mathrm{s}$ in hysteresis, which is four to five orders of 
magnitude smaller than the predicted coefficient. Meanwhile, the coefficient of iodide ions is within this estimated value, which suggests that iodide ions play a more important role in the hysteresis compared with MA ions.

Therefore, more and more evidences consistently suggest that (iii) the migration of iodide ions is the main reason for the hysteretic behavior. Xiao et al [78] proposed that positively charge iodide vacancies $\mathrm{V}_{\mathrm{I}}$ are responsible for the n-type doping in PSC under an external electrical field. Because long time electrical biasing in devices with lateral configured electrodes leads to the obvious degradation at the anode side. To elucidate the species of ions, Yang et al [81] conducted long-term high temperature biasing experiments using a device structure of $\mathrm{Pb} / \mathrm{MAPbI}_{3} / \mathrm{AgI} / \mathrm{Ag}$. The formation of $\mathrm{PbI}_{2}$ characterized by energy dispersive X-ray spectroscopy (EDX) and X-ray diffraction (XRD) indicates that iodide ions result in the observed stoichiometric changes. Similarly, by using XRD and EDX, Yuan et al [82] directly observed the migration of iodide ion at higher temperature $330 \mathrm{~K}$ under the electrical field. During the experiment, $\mathrm{MAPbI}_{3}$ first decomposes into $\mathrm{PbI}_{2}$, which can be driven by the external field. Furthermore, Li et al [10] carried out the X-ray photoemission spectroscopy (XPS) characterization of long-term biased perovskite film with lateral configured electrodes. After 30 min biasing, this perovskite film is measured by XPS, which quantitatively characterize the element distribution within the channel. As shown in Figure 10 (f), it demonstrates that at the positive electrode, the $\mathrm{I} / \mathrm{Pb}$ ratio is 5.67 , whilst, at the ground electrode, the ratio is only 2.7 . This result shows the significant iodine element 
redistribution, in which the ratio $\mathrm{I} / \mathrm{Pb}$ is stoichiometric $\sim 3$ in the pristine device. In addition, shown in Figure 10 (a), the XPS of $\mathrm{Pb}$ reveals the decomposition of $\mathrm{MAPbI}_{3}$ at the ground electrode, which is consistent with the optical microscopy result of Xiao et al [78].
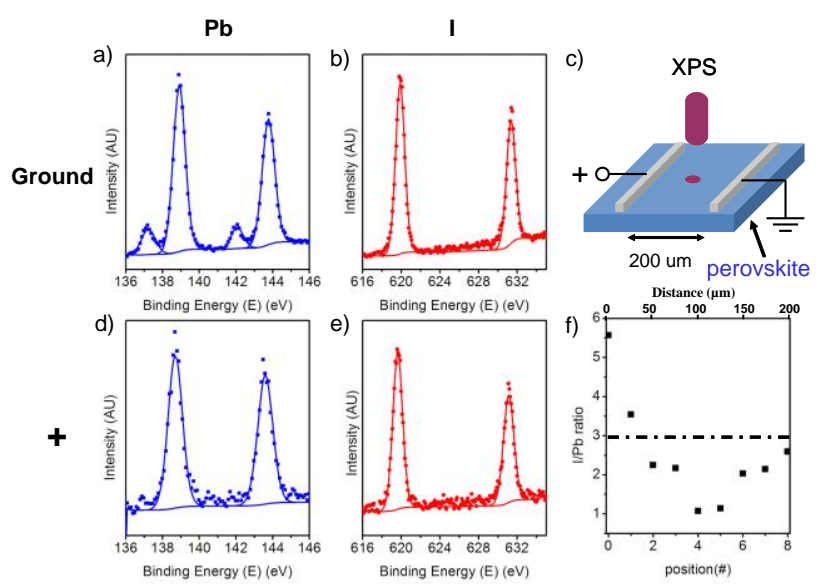

Figure 10 XPS result of a $\mathrm{CH}_{3} \mathrm{NH}_{3} \mathrm{PbI}_{3-\mathrm{x}} \mathrm{Cl}_{\mathrm{x}}$ device with lateral electrodes, a) and b) are XPS spectra of $\mathrm{Pb}$ and I elements near the ground electrode, respectively. d) and e) are the XPS spectra of $\mathrm{Pb}$ and I elements near the positive electrode, respectively. c) Schematic illustration of the set-up for measurement of elements distribution. The applied DC voltage is $1 \mathrm{~V}$ for $30 \mathrm{~min}$. The lateral electrode distance is $200 \mu \mathrm{m}$. f) The ratio of $\mathrm{I} / \mathrm{Pb}$ distribution across the channel after applying bias between two lateral electrodes. The dashed line shows the stoichiometry of perovskite, $\mathrm{I} / \mathrm{Pb} \sim 3$. Reprinted with permissions from [10]. Copyright $(2016$ by John Wiley \& Sons, Inc.

2.3.2 Detailed Migration Process - migration channels.

The detailed migration process of ions in PSCs, maybe treated using within dynamics of defect states. Due to the difficulty of directly characterizing the movement of these ions, most of the description is on the basis of theoretical DFT calculations $[37,80,83]$. 

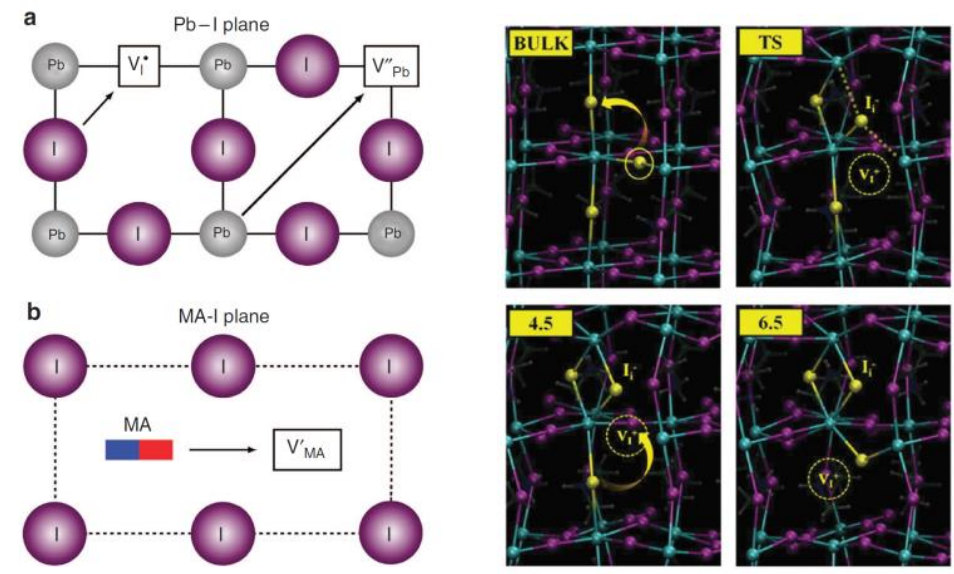

Figure 11. Schematic diagram for the ion migration, especially $\mathrm{I}^{-}$ion, $\mathrm{Pb}^{2+}$ ion and $\mathrm{MA}^{+}$ion, respectively. (a) Iodide ions move along octahedron edge, $\mathrm{Pb}^{2+}$ ions move along diagonal direction. (b) $\mathrm{MA}^{+}$ions move via the neighboring vacancy site. Reprinted with permissions from [80]. Copyright@(2015 Nature Publishing Group. (c) Detailed process of iodide ion migration. (i) Bulk structure is the perfect periodical crystalline structure. (ii) Distance between iodide vacancies and ions increases, denoted as TS states. (iii) and (iv) are the two intimate defect states, two ions distance are $4.5 \AA$ and $6.5 \AA$, respectively. Reprinted with permissions from [83]. Copyright@2016 Royal Society of Chemistry.

Herein, the ionic transport is described as a hopping mechanism, i.e jumping between neighboring sites. As shown in Figure 11, (i) $\mathrm{MA}^{+}$ions migrate into nearby vacant cage, (ii) $\mathrm{Pb}^{2+}$ ions migrate via the diagonal direction, whilst, (iii) iodide ions move along an octahedron in the $\mathrm{Pb}$-I plane [80]. The migration of these ions requires an energy to open the $\mathrm{PbX} 3$ framework, which acts as a barrier for the ionic migration. This barrier is named activation energy $E_{a}$, that will be discussed in detailed in the following part. For the most mobile ions, i.e. iodide ions, Mosconi et al [83] provide detailed description on the basis of theoretical simulation. Accompanying the reorientation of $\mathrm{MA}^{+}$group, the iodide interstitial $\left(\mathrm{I}_{\mathrm{i}}\right)$ forms leaving the iodide vacancies $\left(\mathrm{V}_{\mathrm{I}}\right)$ at the original location. Then, $\mathrm{V}_{\mathrm{I}}$ and $\mathrm{I}_{\mathrm{i}}$ form the $\mathrm{V}_{\mathrm{I}} / \mathrm{I}_{\mathrm{i}}$ pairs, denoting as transition state (TS), as shown in Figure 11(c). Next, by overcoming the activation energy, $\mathrm{V}_{\mathrm{I}}$ and $\mathrm{I}_{\mathrm{i}}$ separate with distance of $4.5 \AA$ and $6.5 \AA$, respectively, generating distinct defects and migrating in the opposite directions in the electrical field, as illustrated in Figure 9. 


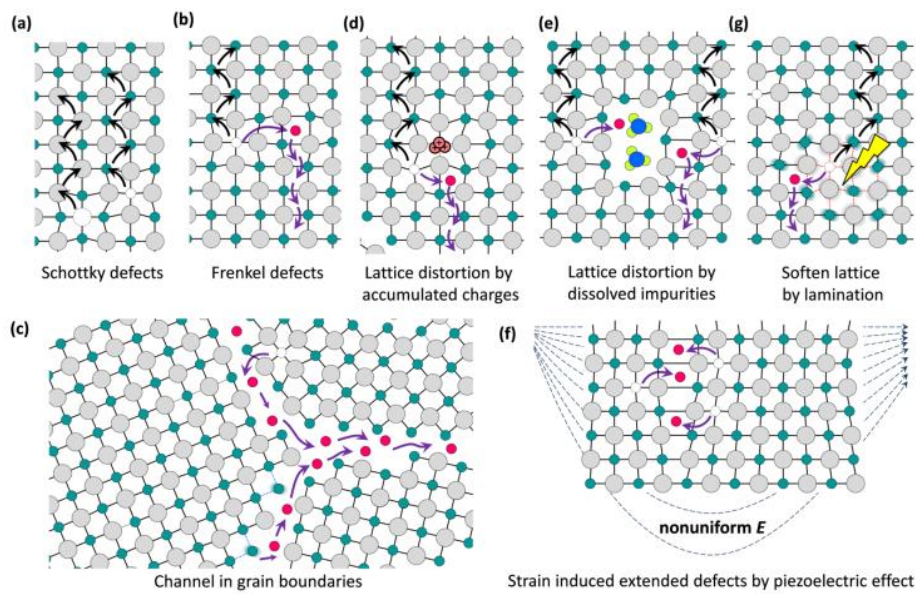

Figure 12. Schematic diagrams for illustrating the ionic migration channels. (a) Schottky defects, or vacancies, (b) Frankel defect, or interstitials defects. (c) Ions migrating at the ground boundary. Distortion of lattice due to (d) accumulation of charges, (e) impurities, (g) light illumination induced lattice soften and (f) piezoelectric effect. Reprinted with permissions from [74]. Copyright@2016 American Chemical Society.

Apart from hopping through point defects in the bulk, there exists other possible ion migration channels. For instance, local lattice distortion, originated from charge accumulation, or additional impurity atoms, light illumination, piezoelectric effects, as shown in Figure 12, provide additional migration channels for the ion transport [74]. Recently, evidences emphasize the importance of GB, illustrated in Figure 12 (c), on the ionic migration. Xiao et [78] found that compared with large crystal size device, film composed of smaller size grains can be more easily switched under external electrical field. By carrying out conducting atomic force microscopy (c-AFM), and SEM, Shao et al [84] indicate that the GB where the defects accumulate is the channel for the ion migration, consequently exhibiting larger hysteresis. Moreover, Yun et al [85] conducted Kelvin probe force microscopy (c-KFM) to reveal that ion migration near GBs is much faster than inside the grains. At the GB, ions exhibit higher diffusivity and more effective charge separation. Xing et al [86] also observed that devices with larger crystal size exhibit higher activation energy, that is, ions have to overcome higher 
barrier to migrate. MacDonald et al [87] reveal that GBs demonstrates the depthdependent resistivity, and this inhomogeneity is one of the limits for the improvement of PSC efficiency. Therefore, with the concern of the importance of GB, further works will be dedicated on their detailed investigation.

\subsubsection{Activation Energy Characterization}

The ionic migration/transport within the bulk of solids[88], especially in traditional perovskite materials $\left(\mathrm{ABO}_{3}\right)$, has been intensively investigated, that, the movement of ions is facilitated by a hopping mechanism among the atomic lattices with assistant of defect states (i.e. vacancies, interstitials etc.) [89]. This hopping process to the neighboring sites requires energy, i.e activation energy $E_{a}$, to overcome the barriers, as shown in Figure 13.

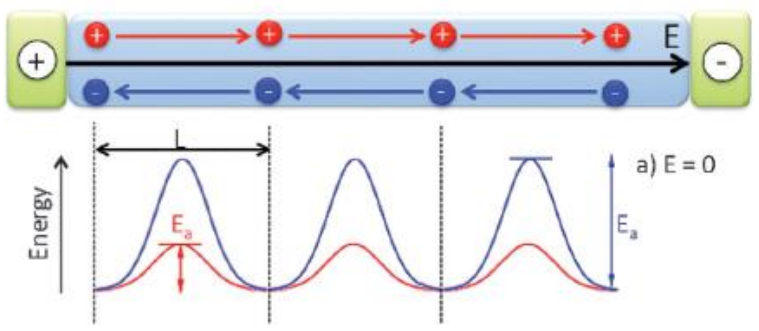

Figure 13. Illustration of ion migration and the energy diagram for the migrating positive and negative ions, via periodical barriers, denoted as activation energy $E_{a}$ here. $\mathrm{L}$ is the distance between the neighboring sites. Reprinted with permissions from [76]. Copyright $\subset 2015$ Royal Society of Chemistry.

Hence, this hopping process, which highly depends on the temperature, is described as a thermally activated point defect movement. The migration ratio, $r_{m}$ is expressed empirically in form of an Arrhenius relation [10,37,90]:

$r_{m} \propto \exp \left(\frac{E_{a}}{k_{B} T}\right)$ 
where $k_{B}$ and $T$ are Boltzmann constant and absolute temperature, respectively. By fitting the slope in temperature dependent measurements, we can obtain the respective activation energy. Since $E_{a}$ strongly relies on the ionic species, determining the value of $E_{a}$ enable us to identify which ions are moving. Concerning different unusual phenomena related with ionic migration, it is feasible to obtain $E_{a}$ in different measurements, as summarized in Table 1. For instance, Meloni et al [37], Eames et al [80], Li et al [10], and Yu et al [90] extract $E_{a}$ by fitting temperature dependent transient $J-V$ curve measurements. Yang et al [81] obtain the $E_{a}$ by carrying out temperature dependent conductivity and dielectric constant measurements. Moscoi et al [83] obtain the $E_{a}$ using the fitting slope of temperature dependent PL dynamic measurements. Based on theoretical calculations, as exhibited in Table 1, the similar $E_{a}$ value, mostly within the range between $0.2 \mathrm{eV}$ and $0.6 \mathrm{eV}$, suggests that iodide ion and MA ions playing the dominated roles inside, rather than $\mathrm{Pb}$ ions. Since the calculated value of $\mathrm{H}$ ion activation energy, i.e. the barrier for the proton migration, is $\sim 0.29 \mathrm{eV}$ [77], currently does not allow to completely rule out the contribution of hydrogen ions in the ionic migration.

Table 1. Summary of activation energy obtained by different measurements.

\begin{tabular}{|c|c|c|c|c|}
\hline No & $\begin{array}{l}\text { Characterization } \\
\text { Method }\end{array}$ & Bulk material & Particle type & $\begin{array}{l}\text { Activation energy } \\
(\mathrm{eV})\end{array}$ \\
\hline \multirow[t]{2}{*}{$1[76]$} & \multirow[t]{2}{*}{ Theoretical calculation } & $\mathrm{MAPbI}_{3}$ film & $\begin{array}{l}V_{\mathrm{I}} \\
\mathrm{V}_{\mathrm{MA}} \\
\mathrm{V}_{\mathrm{Pb}}\end{array}$ & $\begin{array}{l}0.08 \\
0.46 \\
0.8\end{array}$ \\
\hline & & $\mathrm{MAPbBr}_{3}$ film & $\begin{array}{l}\mathrm{V}_{\mathrm{Br}} \\
\mathrm{V}_{\mathrm{MA}}\end{array}$ & $\begin{array}{l}0.09 \\
0.56\end{array}$ \\
\hline \multirow[t]{2}{*}{$2[80]$} & Theoretical calculation & $\mathrm{MAPbI}_{3}$ film & $\begin{array}{l}\mathrm{V}_{\mathrm{I}} \\
\mathrm{V}_{\mathrm{MA}} \\
\mathrm{V}_{\mathrm{Pb}} \\
\end{array}$ & $\begin{array}{l}0.58 \\
0.84 \\
2.31 \\
\end{array}$ \\
\hline & $\begin{array}{l}\text { Short-circuit } \\
\text { photocurrent relaxation }\end{array}$ & $\mathrm{MAPbI}_{3}$ film & $\mathrm{V}_{\mathrm{I}}$ & $0.60-0.68$ \\
\hline 3 & First-principle & $\mathrm{MAPbI}_{3}$ film & $\mathrm{V}_{\mathrm{I}}$ & 0.44 \\
\hline
\end{tabular}




\begin{tabular}{|c|c|c|c|c|}
\hline \multirow[t]{2}{*}{ [91] } & \multirow[t]{2}{*}{ calculation } & \multirow[b]{2}{*}{$\mathrm{FAPbI}_{3}$ film } & $\mathrm{V}_{\mathrm{MA}}$ & 0.57 \\
\hline & & & $\begin{array}{l}V_{I} \\
V_{F A}\end{array}$ & $\begin{array}{l}0.48 \\
0.61\end{array}$ \\
\hline $4[77]$ & $\begin{array}{l}\text { Minimum-energy-path } \\
\text { calculation }\end{array}$ & $\mathrm{MAPbI}_{3}$ film & $\mathrm{H}^{+}$ & 0.29 \\
\hline \multirow[t]{3}{*}{$5[92]$} & \multirow[t]{3}{*}{$\begin{array}{l}\text { Impedance spectra at } \\
\text { different temperatures }\end{array}$} & $\mathrm{MAPbI}_{3}$ film & $\mathrm{MA}^{+}$ion & $\begin{array}{l}0.58(<320 \mathrm{~K}) \\
0.23(>320 \mathrm{~K})\end{array}$ \\
\hline & & $\begin{array}{l}\mathrm{MA}_{x} \mathrm{FA}_{1-x} \mathrm{PbI}_{3} \\
\text { film }\end{array}$ & $\mathrm{MA}^{+} / \mathrm{FA}^{+}$ion & 0.63 \\
\hline & & $\mathrm{FAPbI}_{3}$ film & $\mathrm{FA}^{+}$ion & $\begin{array}{l}0.22(<330 \mathrm{~K}) \\
0.79(>330 \mathrm{~K})\end{array}$ \\
\hline $6[90]$ & $\begin{array}{lr}\text { Temperature- } \\
\text { dependent } & \text { stepwise- } \\
\text { stabilized } & \text { current } \\
\text { responses } & \\
\end{array}$ & $\mathrm{MAPbI}_{3}$ film & $\mathrm{V}_{\mathrm{I}}$ & $0.10-0.18$ (1 Sun) \\
\hline $7[10]$ & $\begin{array}{ll}\text { Temperature- } \\
\text { dependent current } \\
\text { density in dark }\end{array}$ & $\mathrm{MAPbI}_{3-\mathrm{x}} \mathrm{Cl}_{\mathrm{x}}$ film & $\mathrm{I}^{-}$ion & $0.23-0.31$ \\
\hline $8[81]$ & $\begin{array}{l}\text { Temperature- } \\
\text { dependent } \\
\text { conductivity }\end{array}$ & $\mathrm{MAPbI}_{3}$ film & Mobile ions & 0.43 \\
\hline $9[93]$ & Theoretical calculation & $\mathrm{MAPbI}_{3}$ film & Mobile ions & 0.5 \\
\hline $10[79]$ & $\begin{array}{l}\text { Temperature- } \\
\text { dependent conductivity }\end{array}$ & $\mathrm{MAPbI}_{3}$ film & $\mathrm{MA}^{+}$ion & 0.36 \\
\hline $11[94]$ & $\begin{array}{l}\text { Growth rate of PL peak } \\
\text { at different temperature }\end{array}$ & $\mathrm{MAPbBr}_{3-\mathrm{x}} \mathrm{I}_{3}$ & $\mathrm{Br}$ and $\mathrm{I}$ ion & 0.27 \\
\hline $12[83]$ & $\begin{array}{l}\text { Rate of PL rise at } \\
\text { different temperatures }\end{array}$ & $\mathrm{MAPbI}_{3}$ film & $\mathrm{V}_{\mathrm{I}}$ & 0.137 \\
\hline $13[71]$ & $\begin{array}{l}\text { Rate of PL rise at } \\
\text { different temperatures }\end{array}$ & $\mathrm{MAPbI}_{3}$ film & $\mathrm{V}_{\mathrm{I}}$ & 0.19 \\
\hline $14[95]$ & $\begin{array}{l}\text { Grain growth exponent } \\
\text { at different temperature }\end{array}$ & $\mathrm{MAPb}\left(\mathrm{I}_{0.6} \mathrm{Br}_{0.4)_{3}}\right.$ & Mobile ion & 0.3 \\
\hline \multirow[t]{2}{*}{$15[86]$} & \multirow[t]{2}{*}{$\begin{array}{l}\text { Temperature- } \\
\text { dependent conductivity }\end{array}$} & $\mathrm{MAPbI}_{3}$ film & Mobile ion & $\begin{array}{l}0.08-0.14(0.25 \text { sun }) \\
0.27-0.50 \text { (dark) }\end{array}$ \\
\hline & & $\begin{array}{l}\mathrm{MAPbI}_{3} \quad \text { single } \\
\text { crystal }\end{array}$ & Mobile ion & $\begin{array}{l}0.47 \text { (0.25 sun) } \\
1.05 \text { (dark) }\end{array}$ \\
\hline \multirow[t]{4}{*}{$16[37]$} & \multirow{2}{*}{$\begin{array}{l}\text { Current difference } \\
\text { between forward and } \\
\text { reverse voltage scan at } \\
\text { different temperatures } \\
\text { Theoretical calculation }\end{array}$} & $\mathrm{MAPbI}_{3}$ film & Mobile ion & $0.314-0.341$ (1 sun) \\
\hline & & $\mathrm{MAPbBr}_{3}$ film & Mobile ion & 0.168 (1 sun) \\
\hline & \multirow[t]{2}{*}{ Theoretical calculation } & $\mathrm{MAPbI}_{3}$ film & $\begin{array}{l}\mathrm{V}_{\mathrm{I}} \\
\mathrm{V}_{\mathrm{MA}} \\
\mathrm{V}_{\mathrm{Pb}}\end{array}$ & $\begin{array}{l}0.28-0.45 \\
0.7-1.12 \\
1.39-1.78 \\
\end{array}$ \\
\hline & & $\mathrm{MAPbBr}_{3}$ film & $\begin{array}{l}\mathrm{V}_{\mathrm{Br}} \\
\mathrm{V}_{\mathrm{MA}} \\
\mathrm{V}_{\mathrm{Pb}}\end{array}$ & $\begin{array}{l}0.27-0.29 \\
0.7-1.2 \\
0.94-1.22\end{array}$ \\
\hline $17[96]$ & $\begin{array}{l}\text { Temperature shift in the } \\
\text { capacitance derivative } \\
\text { peak }\end{array}$ & $\mathrm{MAPbI}_{3-\mathrm{x}} \mathrm{Cl}_{\mathrm{x}}$ film & $\begin{array}{l}\text { Electrode } \\
\text { polarization }\end{array}$ & $\begin{array}{l}0.45 \text { (low temperature) } \\
0.25 \quad \text { (high } \\
\text { temperature) }\end{array}$ \\
\hline $18[46]$ & $\begin{array}{l}\text { Molecular dynamics } \\
\text { simulation }\end{array}$ & $\mathrm{MAPbI}_{3}$ crystal & $\begin{array}{l}V_{I} \\
I_{i}\end{array}$ & $\begin{array}{l}0.1 \\
0.24\end{array}$ \\
\hline
\end{tabular}

Apart from the impact of chemical structure, or stoichiometric [90], external optical field can also significantly change the activation energy. It is found that the illuminated 
light can decrease the barrier of hopping, i.e. activation. Xing et al [86] observed that under 0.25 Sun light illumination condition, the activation energy decreases from 0.27 $\mathrm{eV}$ to $0.08 \mathrm{eV}$ in polycrystalline, from $1.05 \mathrm{eV}$ to $0.47 \mathrm{eV}$ in single crystal, compared with dark conditions. This result also shows that single crystals exhibit a higher activation energy than polycrystalline ones, consistent with the previous theory on ionic migration through GB.
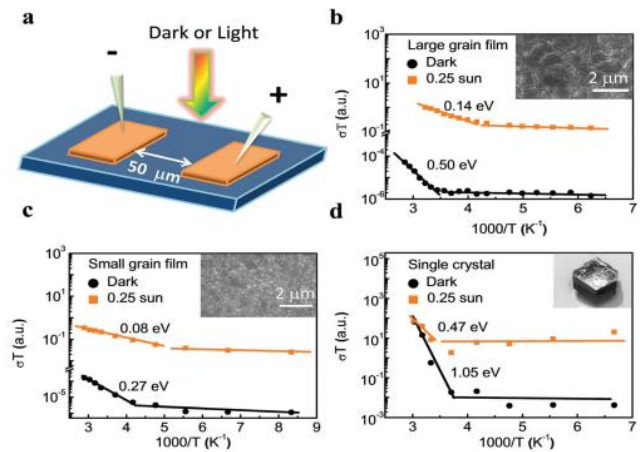

Figure 14. (a) Schematic diagram of a device structure for characterizing the activation energy, with different crystal size and with/without illumination. (b)Devices with large grain size ( 1 um), (c) smaller size ( 300 nm) and (d) single crystal, exhibits different $E_{a}$ in the dark and light illumination condition, respectively. Reprinted with permissions from [86]. Copyright $\subset 2015$ Royal Society of Chemistry.

\subsubsection{Energy band bending}

To fully understand the influence of ionic migration on the device performance, an energy level diagram is a useful approach to illustrate the detailed process, not only the field distribution inside, but also the interfacial barriers. Several groups have made efforts on the construction of a band diagram, based on indirect evidences, such as transient photocurrent [80] and surface potential characterization [85]. Furthermore electroabsorption spectroscopy [97-99] has proven as a powerful approach to study the internal electrical field, enabling to directly characterize the field of device in working condition and observe any occurring interfacial barrier modulations [100]. Li et al 
[10]found that there is a shift of the built-in potential during the device scanning, as shown in Figure 15. In addition, the shift of the potential $\xi$ is equivalent with the change of open circuit voltage, $V_{o c}$. This indicates the modulation of $V_{o c}$ is ascribed to a change in the internal field, caused by ion migration.

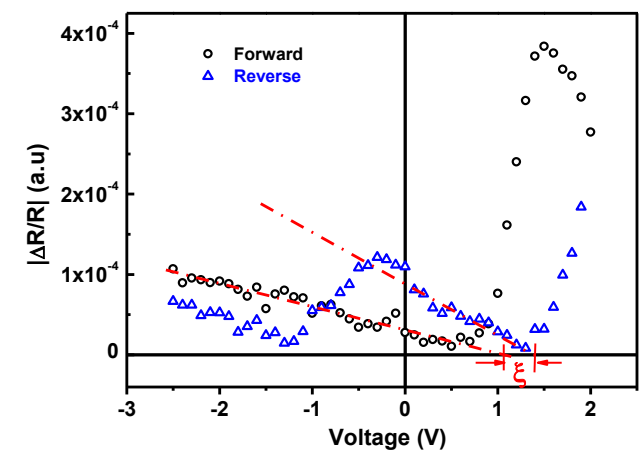

Figure 15. Voltage dependent electroabsorption signal in a standard perovskite solar cells, during the forward and reversed scanning process. There exists the shift of built-in potential $\xi$, which correlates with the shift of $\mathrm{V}_{\text {oc }}$. Reprinted with permissions from [10]. Copyright $(2016$ by John Wiley \& Sons, Inc.

Therefore, based on above evidence, the band diagram influenced by the ionic migration is exhibited in Figure 16 [80]. To simplify the discussion, the work function of both electrodes are the same. Without external electrical field, according to a classical Metal-Insulate-Metal (MIM) model, the voltage drops across the whole film exhibited as Figure 16 (a). When the device is applied field, the ions, i.e. positive and negative ones are driven towards opposite selective electrodes [78]. These ions accumulate at the electrode, causing: (1) changing the internal field of the device (2) modulating the perovskite/electrode interfacial barriers. For the first influence, as shown in Figure 16, it indicates that the accumulated charges, positive and negative ones at the opposite electrodes, generating additional electrical field. This field can either enhance or decrease the original field. Consequently, the separation of photogenerated charges can be improved or deteriorated [80]. (2) Apart from the influence of internal field, 
accumulated charges also can modulate the interfacial barriers. The drifted ions seem to be located at the interface between perovskite and selective electrode result in the manipulation of charge injection/extraction barriers, characterized by electroabsorption spectroscopy. In this respect, the effective charge transfer process through these interface can be modulated by the ions, which is driven by the external electrical field [101]
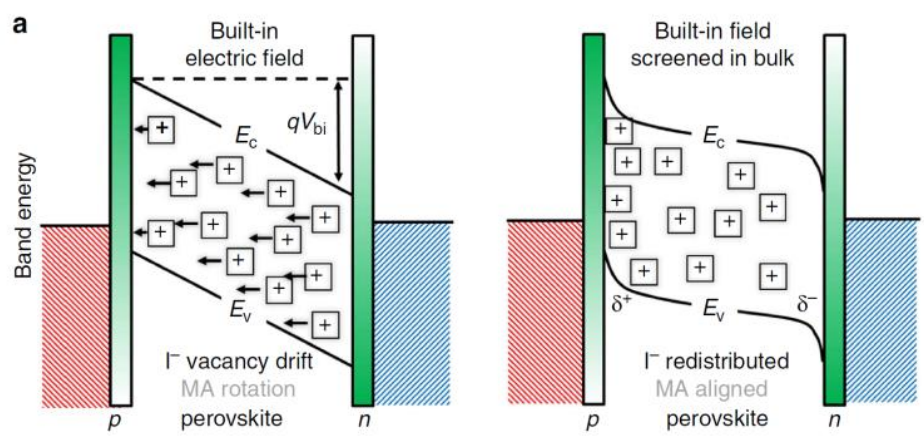

Figure 16 Schematic diagram indicating the influence of migrating ions on the band structure under external electrical field. (a) Before migration, the voltage drops across the perovskite film uniformly. (b) After the redistribution of ions, the internal field is shielded by the accumulated ions at the interfaces. Adapted with permissions from [80]. Copyright $\subset 2015$ Nature Publishing Group.

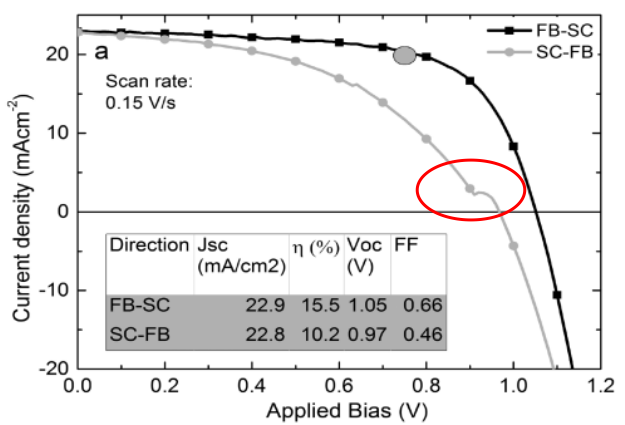

Figure 17. A typical hysteresis behavior in a J-V curve scanning, exhibiting a shift at the flat band conditions, indicated by a red circuit. Reprinted with permissions from [15]. Copyright $\bigcirc 2014$ American Chemical Society.

Li et al [10] also mention the observed kinks illustrated in Figure 1 in the $J-V$ curve measurement. There are several groups which have also observed similar behavior $[15,16,26,102,103]$, especially during fast scanning, as shown in Figure 17. This model of ion migration, which influences the internal field of the device, provides an 
explanation for this kink in the $J-V$ curve measurement. When scanning from a negative bias, the flat band condition is reached. In the flat band condition, where there is no electrical field inside at this stage, ion diffusion due to ion concentration gradient (without ion drift) rearranges the internal field which leads to the shift of $V_{\text {oc. }}$ Therefore, this kink in the $J-V$ curve is another evidence for the ionic migration during the electrical sweeping.

\section{Suppression of the hysteresis}

Concerning the origin of the hysteresis, as we proposed, ionic migration associated with charge trapping/detrapping, it seems useful to suppress the hysteresis through three approaches: (1) reducing the amount of ions, which are ascribed from the defect states. (2) decreasing the migration of these ions and (3) promoting the interfacial charge transfer process.

\subsection{Larger crystal size}

It is found that devices with larger crystal size exhibit less hysteresis behavior [104]. There are two possible reasons: (1) larger crystal size decrease the defects states, which are accumulated at GB. (2) The amount of GB, which perform as channels for the ion migration, decreases as the crystal size increases in the devices.

Furthermore, recently Xing et al [86] found that when increasing the grain size in the device, the activation energy of ionic migration also increases. For the single crystal, the activation energy increase to $1.05 \mathrm{eV}$ in the dark condition. This increased activation 
energy suggests higher energy barrier for the migration of ions.

\subsection{Incorporation of PCBM molecules}

a)

b)
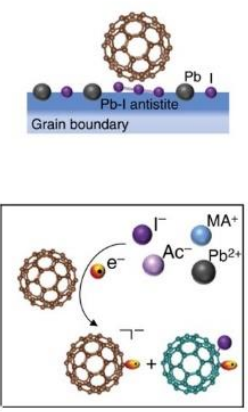

c)

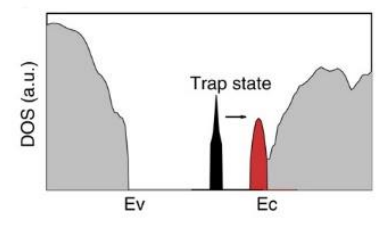

Figure 18. Mechanism for the reduction of hysteresis by using PCBM. (a) Passivation process of PCBM on perovskite. PCBM absorbs on the antistite defects located at the GB. (b) electron transfer occurs between the perovskite anions and PCBM, forming PCBM-halide radical. (c) Theory calculation (DFT) indicates that charge transfer leads to the transition of trap state from deep trap towards shallow traps. Adapted with permissions from [58]. Copyright $\subset 2015$ Nature Publishing Group.

It is widely observed that devices involving PCBM molecules, either using as selective ETL [105] or mixing as bulk heterojunction [57], exhibit much less hysteresis. As previously discussed, these ions are driven by the external field and accumulate at the interface between perovskite/ETL and HTL. This accumulation leads to the local high $\mathrm{p}$ and $\mathrm{n}$ doping, effectively enhancing/decreasing the built-in potential. Meanwhile, these ions also change the interfacial barrier in the device, resulting in the hysteresis in $J-V$ curves. While, in perovskite solar cells incorporating with single PCBM layer or perovskite/PCBM mixture layer, PCBM molecules distribute within the bulk of perovskite film. As shown in Figure 18, absorbed at perovskite defective sites in the vicinity of GBs, these PCBM molecules passivate theses defects states, e.g iodide interstitials or iodide vacancies, giving rise to the decrease or even halting of ion migration in perovskite film. Xu et al. [58] have demonstrated the formation of PCBM- 
halide radical in perovskite-PCBM hybrid solution using UV-Vis absorption. In detail, by direct electron transfer from anions (iodide ions here) to PCBM or fullerene, iodide ions from defects form strong bonding with PCBM molecules. This production of anionic fullerene derivatives originates from the reaction between PCBM and $\mathrm{I}_{3}$ trimer, associated with the $\mathrm{Pb}-\mathrm{I}$ antisite defects [74]. In this respect, the iodide ions/defects are immobilized by combining with the PCBM molecules in the bulk of perovskite. In addition, PCBM is able to passivate the surface state, improving the charge transfer process through the perovskite/ETL interface [60]. Even though ions accumulate at the interface, effective charge transfer barrier is not established. Thus, hysteresis is significantly suppressed due to the reduction of ionic migration as well as the interfacial barriers.

\section{Application in devices}

\subsection{Photovoltaic device}

It has been demonstrated that the long-time biasing leads to the redistribution of ions [10]. The designed ionic distribution can enhance the internal field inside and decrease the interfacial barriers, thus improving the device performance. This is the main reason for the pre-biasing procedure before the standard $J-V$ curve characterization $[38,101]$. In the next step, optimistically we can immobilize these ions at the proper position, beneficial for power conversion efficiency. In addition, controlled $p$ and $n$ doping induced by an external electrical field [80] allows to further modulate the properties in

PSCs. With this approach it is possible to achieve a perovskite PN junction with 
different doping in different regions [106].

\subsection{Memory device}
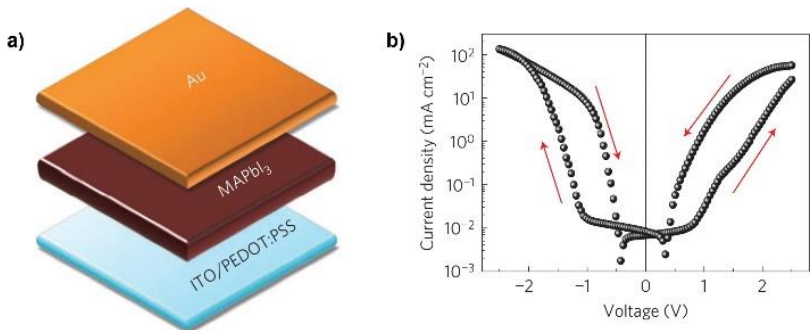

Figure 19. (a) Schematic of the perovskite switching device. (b) Resistive switching behavior measured in J-V curve. Reprinted with permissions from [78]. Copyright@2014 Nature Publishing Group.

Xiao et al [78] realized the switchable photovoltaic devices by employing the ionic migration mechanism. As shown in Figure 19, different direction poling results in different photovoltaic performance in this single layer vertical structure. This demonstrates the potential application in the memory devices. By utilizing the structure of $\mathrm{Ag} /$ perovskite/Pt, Choi et al [107] realized the low voltage multilevel resistive switching devices with high ON/OFF ratio. Furthermore, Gu et al [108] achieved the flexible perovskite memory device by depositing perovskite precursor solution on transparent plastic substrates coated with conducting layer. Therefore, by utilizing this resistive switching property, it is feasible to open a pathway to fabricate low-cost flexible high-speed memory devices.

\section{Conclusion}

In this Review, we first summarize the features of hysteresis behaviors in perovskite solar cells. Then the possible mechanisms for this behavior are discussed in detail, 
including ferroelectricity, charge trapping/detrapping, as well as ionic migration under the external electrical field. Recent experimental and theoretical results consistently support the ion migration and charge trapping/detrapping, as mains factor for the hysteresis. Next, we investigate aspects of the migration in detail, such as the species of ion, migration channel, activation energy and its influence on the band structure. Forth, to eliminate or alleviate hysteresis, we show the approaches, i.e. improving crystalline size, and involvement of PCBM molecules for passivation. Furthermore, we demonstrate the potential application of hysteresis, such as the $p$ and $n$ type doping due to ion migration as well as the memristive switching device. In the end, it is necessary to emphasize that perovskite, in which strong coupling between ionic migration and free charge carriers transport, has to be carefully addressed, as these mobile defects/ions inside can be modulated by both external optical/electrical field and crystalline structure or chemical passivation.

\section{Acknowledgement:}

$\mathrm{CL}, \mathrm{YZ}$ and $\mathrm{SH}$ acknowledge financial support from Bavarian frame work program

“Solar Technologies go Hybrid". CL is grateful to Dr. Hui Yu for valuable discussions. AG acknowledges financial support from MINECO of Spain under project (MAT201347192-C3-1-R) on the DISOLAR2 Project (PROMETEOII/2014/020), and from the Generalitad Valenciana and Spanish Ministerio de Economía y Competitividad through a Ramón y Cajal Fellowship (RYC-2014-16809). 


\section{References:}

[1] http://www.nrel.gov/pv/assets/images/efficiency chart.jpg

[2] Stoumpos C C, Malliakas C D and Kanatzidis M G 2013 Semiconducting Tin and Lead Iodide Perovskites with Organic Cations: Phase Transitions, High Mobilities, and Near-Infrared Photoluminescent Properties Inorg. Chem. 52, 9019-9038

[3] McMeekin D P et al. 2016 A mixed-cation lead mixed-halide perovskite absorber for tandem solar cells Science 351, 151-155

[4] Eperon G E, Stranks S D, Menelaou C, Johnston M B, Herz L M and Snaith H J 2014 Formamidinium lead trihalide: a broadly tunable perovskite for efficient planar heterojunction solar cells Energy Environ. Sci. 7, 982-988

[5] Stranks S D, Eperon G E, Grancini G, Menelaou C, Alcocer M J P, Leijtens T, Herz L M, Petrozza A and Snaith H J 2013 Electron-hole diffusion lengths exceeding 1 micrometer in an organometal Trihalide Perovskite absorber Science 342, 341-344

[6] Xing G, Mathews N, Sun S, Lim S S, Lam Y M, Grätzel M, Mhaisalkar S and Sum T C 2013 Long-Range Balanced Electron and Hole Transport Lengths in Organic-Inorganic CH3NH3PbI3 Science 342, 344-347

[7] Zhou H, Chen Q, Li G, Luo S, Song T B, Duan H S, Hong Z, You J, Liu Y and Yang Y 2014 Interface engineering of highly efficient perovskite solar cells Science 345, 542-546

[8] Wei Z, Chen H, Yan K and Yang S 2014 Inkjet Printing and Instant Chemical Transformation of a CH3NH3PbI3/Nanocarbon Electrode and Interface for Planar Perovskite Solar Cells Angew. Chem. Int. Ed. 53, 13239-13243

[9] Mei A et al. 2014 A hole-conductor-free, fully printable mesoscopic perovskite solar cell with high stability Science 345, 295-298

[10] Li C, Tscheuschner S, Paulus F, Hopkinson P E, Kießling J, Köhler A, Vaynzof Y and Huettner S 2016 Iodine Migration and its Effect on Hysteresis in Perovskite Solar Cells Adv. Mater. 28, 2446-2454

[11] Strukov D B, Snider G S, Stewart D R and Williams R S 2008 The missing memristor found Nature 453, 80-83

[12] Prodromakis T, Toumazou C and Chua L 2012 Two centuries of memristors Nat. Mater. 11, 478481

[13] Jo S H, Chang T, Ebong I, Bhadviya B B, Mazumder P and Lu W 2010 Nanoscale Memristor Device as Synapse in Neuromorphic Systems Nano. Lett. 10, 1297-1301

[14] Sawa A 2008 Resistive switching in transition metal oxides Mater. Today 11, 28-36

[15] Snaith H J, Abate A, Ball J M, Eperon G E, Leijtens T, Noel N K, Stranks S D, Wang J T-W, Wojciechowski K and Zhang W 2014 Anomalous Hysteresis in Perovskite Solar Cells J. Phys. Chem. Lett. 5, 1511

[16] Sanchez R S, Gonzalez-Pedro V, Lee J-W, Park N-G, Kang Y S, Mora-Sero I and Bisquert J 2014 Slow Dynamic Processes in Lead Halide Perovskite Solar Cells. Characteristic Times and Hysteresis J. Phys. Chem. Lett. 5, 2357 
[17] Gottesman R, Haltzi E, Gouda L, Tirosh S, Bouhadana Y, Zaban A, Mosconi E and De Angelis F 2014 Extremely Slow Photoconductivity Response of CH3NH3PbI3 Perovskites Suggesting Structural Changes under Working Conditions J Phys. Chem. Lett. 5, 2662-2669

[18] Kim H S and Park N-G 2014 Parameters Affecting I-V Hysteresis of CH 3 NH 3 PbI 3 Perovskite Solar Cells: Effects of Perovskite Crystal Size and Mesoporous TiO 2 Layer J. Phys. Chem. Lett. 5, 2927

[19] Quarti C, Mosconi E and De Angelis F 2014 Interplay of Orientational Order and Electronic Structure in Methylammonium Lead Iodide: Implications for Solar Cell Operation Chem. Mater. 26, 6557-6569

[20] Bakulin A A et al. 2015 Real-Time Observation of Organic Cation Reorientation in Methylammonium Lead Iodide Perovskites J Phys. Chem. Lett. 6, 3663-3669

[21] Litvin D 1986 Ferroelectric space groups Acta Cryst. A42, 44-47

[22] Sherkar T S and Jan Anton Koster L 2016 Can ferroelectric polarization explain the high performance of hybrid halide perovskite solar cells? Phys. Chem. Chem. Phys. 18, 331-338

[23] Frost J M, Butler K T, Brivio F, Hendon C H, Van Schilfgaarde M and Walsh A 2014 Atomistic origins of high-performanc1. Frost, J. M. et al. Atomistic origins of high-performance in hybrid halide perovskite solar cells. Nano Lett. 14, 2584-90 (2014).e in hybrid halide perovskite solar cells. Nano. Lett. 14, 2584-2590

[24] Zheng F, Takenaka H, Wang F, Koocher N Z and Rappe A M 2015 First-Principles Calculation of the Bulk Photovoltaic Effect in CH3NH3PbI3 and CH3NH3PbI3-xClx J Phys. Chem. Lett. 6, 31-37

[25] Liu S, Zheng F, Koocher N Z, Takenaka H, Wang F and Rappe A M 2015 Ferroelectric Domain Wall Induced Band Gap Reduction and Charge Separation in Organometal Halide Perovskites J Phys. Chem. Lett. 6, 693-699

[26] Wei J, Zhao Y, Li H, Li G, Pan J, Xu D, Zhao Q and Yu D 2014 Hysteresis Analysis Based on the Ferroelectric Effect in Hybrid Perovskite Solar Cells J. Phys. Chem. Lett. 5, 3937

[27] Quarti C, Grancini G, Mosconi E, Bruno P, Ball J M, Lee M M, Snaith H J, Petrozza A and Angelis F D 2014 The Raman Spectrum of the CH3NH3PbI3 Hybrid Perovskite: Interplay of Theory and Experiment $J$ Phys. Chem. Lett. 5, 279-284

[28] Ziffer M E, Mohammed J C and Ginger D S 2016 Electroabsorption Spectroscopy Measurements of the Exciton Binding Energy, Electron-Hole Reduced Effective Mass, and Band Gap in the Perovskite CH3NH3PbI3 ACS Photon. 3, 1060-1068

[29] Wu X, Yu H, Li L, Wang F, Xu H and Zhao N 2015 Composition-Dependent Light-Induced Dipole Moment Change in Organometal Halide Perovskites J. Phys. Chem. C 119, 1253-1259

[30] Chen B, Shi J, Zheng X, Zhou Y, Zhu K and Priya S 2015 Ferroelectric solar cells based on inorganic-organic hybrid perovskites J. Mater. Chem. A 3, 7699-7705

[31] Coll M, Gomez A, Mas-Marza E, Almora O, Garcia-Belmonte G, Campoy-Quiles M and Bisquert J 2015 Polarization Switching and Light-Enhanced Piezoelectricity in Lead Halide Perovskites J Phys. Chem. Lett. 6, 1408-1413

[32] Kutes Y, Ye L, Zhou Y, Pang S, Huey B D and Padture N P 2014 Direct Observation of Ferroelectric Domains in Solution-Processed CH3NH3PbI3 Perovskite Thin Films $J$ Phys. Chem. Lett. 5, 3335-3339

[33] Frost J M, Butler K T and Walsh A 2014 Molecular ferroelectric contributions to anomalous hysteresis in hybrid perovskite solar cells APL Materials 2, 081506 
[34] Chen H-W, Sakai N, Ikegami M and Miyasaka T 2015 Emergence of Hysteresis and Transient Ferroelectric Response in Organo-Lead Halide Perovskite Solar Cells J Phys. Chem. Lett. 6, 164-169

[35] Leguy A M A et al. 2015 The dynamics of methylammonium ions in hybrid organic-inorganic perovskite solar cells Nat. Commun. 6, 7124

[36] Fan Z, Xiao J, Sun K, Chen L, Hu Y, Ouyang J, Ong K P, Zeng K and Wang J 2015 Ferroelectricity of CH3NH3PbI3 Perovskite J. Phys. Chem. Lett. 6, 1155

[37] Meloni S et al. 2016 Ionic polarization-induced current-voltage hysteresis in $\mathrm{CH} 3 \mathrm{NH} 3 \mathrm{PbX} 3$ perovskite solar cells Nat. Commun. 7, 10334

[38] Chen B, Yang M, Priya S and Zhu K 2016 Origin of J-V Hysteresis in Perovskite Solar Cells J Phys. Chem. Lett. 7, 905-917

[39] Ono L K and Qi Y 2016 Surface and Interface Aspects of Organometal Halide Perovskite Materials and Solar Cells J Phys. Chem. Lett. 7, 4764-4794

[40] Miller D W, Eperon G E, Roe E T, Warren C W, Snaith H J and Lonergan M C 2016 Defect states in perovskite solar cells associated with hysteresis and performance Appl. Phys. Lett. 109, 153902

[41] Singh S, Li C, Panzer F, Narasimhan K L, Graeser A, Gujar T P, Köhler A, Thelakkat M, Huettner S and Kabra D 2016 Effect of Thermal and Structural Disorder on the Electronic Structure of Hybrid Perovskite Semiconductor CH3NH3PbI3 J Phys. Chem. Lett. 7, 3014-3021

[42] Green M A, Ho-Baillie A and Snaith H J 2014 The emergence of perovskite solar cells Nat. Photon. 8, 506

[43] Wetzelaer G-J A H, Scheepers M, Sempere A M, Momblona C, Ávila J and Bolink H J 2015 Trap-Assisted Non-Radiative Recombination in Organic-Inorganic Perovskite Solar Cells $A d v$. Mater. 27, 1837-1841

[44] Shockley W and Queisser H J 1961 Detailed Balance Limit of Efficiency of p - n Junction Solar Cells J. Appl. Phys. 32, 510-519

[45] Miller O D, Yablonovitch E and Kurtz S R 2012 Intense internal and external fluorescence as solar cell approach the SQ efficiency limit IEEE J. Photovolt. 2, 303-311

[46] Delugas P, Caddeo C, Filippetti A and Mattoni A 2016 Thermally Activated Point Defect Diffusion in Methylammonium Lead Trihalide: Anisotropic and Ultrahigh Mobility of Iodine $J$ Phys. Chem. Lett. 7, 2356-2361

[47] Wu X, Trinh M T, Niesner D, Zhu H, Norman Z, Owen J S, Yaffe O, Kudisch B J and Zhu X-Y 2015 Trap States in Lead Iodide Perovskites J. Am. Chem. Soc. 137, 2089

[48] D'Innocenzo V, Grancini G, Alcocer M J P, Kandada A R S, Stranks S D, Lee M M, Lanzani G, Snaith H J and Petrozza A 2014 Excitons versus free charges in organo-lead tri-halide perovskites. Nat. Commun. 5, 3586

[49] Yamada Y, Nakamura T, Endo M, Wakamiya A and Kanemitsu Y 2014 Photocarrier Recombination Dynamics in Perovskite $\mathrm{CH}_{3} \mathrm{NH}_{3} \mathrm{PbI}_{3}$ for Solar Cell Applications J. Am. Chem. Soc. 136, 11610-11613

[50] Duan H-S, Zhou H, Chen Q, Sun P, Luo S, Song T-B, Bob B and Yang Y 2015 The identification and characterization of defect states in hybrid organic-inorganic perovskite photovoltaics Phys. Chem. Chem. Phys. 17, 112-116

[51] Shao Y, Xiao Z, Bi C, Yuan Y and Huang J 2014 Origin and elimination of photocurrent hysteresis by fullerene passivation in $\mathrm{CH} 3 \mathrm{NH} 3 \mathrm{PbI} 3$ planar heterojunction solar cells Nat. 
Commun. 5, 5784

[52] Yin W-J, Shi T and Yan Y 2014 Unusual defect physics in CH3NH3PbI3 perovskite solar cell absorber Appl. Phys. Lett. 104, 063903

[53] Motti S G, Gandini M, Barker A J, Ball J M, Srimath Kandada A R and Petrozza A 2016 Photoinduced Emissive Trap States in Lead Halide Perovskite Semiconductors ACS Energy Lett. 1, 726-730

[54] Noel N K, Abate A, Stranks S D, Parrott E S, Burlakov V M, Goriely A and Snaith H J 2014 Enhanced Photoluminescence and Solar Cell Performance via Lewis Base Passivation of Organic-Inorganic Lead Halide Perovskites ACS Nano 8, 9815-9821

[55] Dane W d, Vorpahl S M, Stranks S D, Nagaoka H, Eperon G E, Ziffer M E, Snaith H J and Ginger D S 2015 Impact of microstructure on local carrier lifetime in perovskite solar cells Science 348, 683

[56] Zhang W et al. 2015 Enhanced optoelectronic quality of perovskite thin films with hypophosphorous acid for planar heterojunction solar cells Nat. Commun. 6, 10030

[57] Chiang C-H and Wu C-G 2016 Bulk heterojunction perovskite-PCBM solar cells with high fill factor Nat. Photon. 10, 196-200

[58] Xu J et al. 2015 Perovskite-fullerene hybrid materials suppress hysteresis in planar diodes Nat. Commun. 6, 7081

[59] Wojciechowski K et al. 2014 Heterojunction Modification for Highly Efficient OrganicInorganic Perovskite Solar Cells ACS Nano 8, 12701-12709

[60] Xing G, Wu B, Chen S, Chua J, Yantara N, Mhaisalkar S, Mathews N and Sum T C 2015 Interfacial Electron Transfer Barrier at Compact TiO2/CH3NH3PbI3 Heterojunction Small 11, 3606

[61] Bergmann V W, Guo Y, Tanaka H, Hermes I M, Li D, Klasen A, Bretschneider S A, Nakamura E, Berger R and Weber S A L 2016 Local Time-Dependent Charging in a Perovskite Solar Cell ACS Appl. Mater. Inerfaces 8, 19402-19409

[62] Bergmann V W, Weber S A L, Javier Ramos F, Nazeeruddin M K, Grätzel M, Li D, Domanski A L, Lieberwirth I, Ahmad S and Berger R 2014 Real-space observation of unbalanced charge distribution inside a perovskite-sensitized solar cell Nat. Commun. 5, 5001

[63] Edri E, Kirmayer S, Henning A, Mukhopadhyay S, Gartsman K, Rosenwaks Y, Hodes G and Cahen D 2014 Why Lead Methylammonium Tri-Iodide Perovskite-Based Solar Cells Require a Mesoporous Electron Transporting Scaffold (but Not Necessarily a Hole Conductor) Nano Lett. 14, 1000-1004

[64] Edri E, Kirmayer S, Mukhopadhyay S, Gartsman K, Hodes G and Cahen D 2014 Elucidating the charge carrier separation and working mechanism of $\mathrm{CH} 3 \mathrm{NH} 3 \mathrm{PbI} 3-\mathrm{xClx}$ perovskite solar cells Nat. Commun. 5, 3461

[65] van Reenen S, Kemerink M and Snaith H J 2015 Modeling Anomalous Hysteresis in Perovskite Solar Cells J Phys. Chem. Lett. 6, 3808-3814

[66] Leijtens T, Eperon G E, Barker A J, Grancini G, Zhang W, Ball J M, Kandada A R S, Snaith H $\mathrm{J}$ and Petrozza A 2016 Carrier trapping and recombination: the role of defect physics in enhancing the open circuit voltage of metal halide perovskite solar cells Energy environ. Sci. 9, 3472-3481

[67] Tress W, Marinova N, Moehl T, Zakeeruddin S M, Nazeeruddin M K and Gratzel M 2015 Understanding the rate-dependent $\mathrm{J}-\mathrm{V}$ hysteresis, slow time component, and aging in 
CH3NH3PbI3 perovskite solar cells: the role of a compensated electric field Energy. Environ. Sci. 8, 995

[68] Richardson G, O'Kane S E J, Niemann R G, Peltola T A, Foster J M, Cameron P J and Walker A B 2016 Can slow-moving ions explain hysteresis in the current-voltage curves of perovskite solar cells? Energy environ. Sci. 9, 1476-1485

[69] Tian Y, Merdasa A, Peter M, Abdellah M, Zheng K, Ponseca C S, Pullerits T, Yartsev A, Sundström V and Scheblykin I G 2015 Giant photoluminescence blinking of perovskite nanocrystals reveals single-trap control of luminescence Nano Lett. 15, 1603-1608

[70] Zhao T, Chueh C-C, Chen Q, Rajagopal A and Jen A K Y 2016 Defect Passivation of OrganicInorganic Hybrid Perovskites by Diammonium Iodide toward High-Performance Photovoltaic Devices ACS Energy Lett. 1, 757-763

[71] deQuilettes D W, Zhang W, Burlakov V M, Graham D J, Leijtens T, Osherov A, Bulović V, Snaith H J, Ginger D S and Stranks S D 2016 Photo-induced halide redistribution in organicinorganic perovskite films Nat. Commun. 7, 11683

[72] Chen S, Wen X, Huang S, Huang F, Cheng Y-B, Green M and Ho-Baillie A 2016 Light Illumination Induced Photoluminescence Enhancement and Quenching in Lead Halide Perovskite Solar RRL, DOI: 10.1002/solr.201600001

[73] Li C, Zhong Y, Luna C, Unger T, Deichsel K, Gräser A, Köhler J, Köhler A, Hildner R and Huettner S 2016 Emission Enhancement and Intermittency in Polycrystalline Organolead Halide Perovskite Films Molecules 21, 1081-1081

[74] Yuan Y and Huang J 2016 Ion Migration in Organometal Trihalide Perovskite and Its Impact on Photovoltaic Efficiency and Stability Acc. Chem. Res. 49, 286-293

[75] Frost J M and Walsh A 2016 What Is Moving in Hybrid Halide Perovskite Solar Cells? Acc. Chem. Res. 49, 528-535

[76] Azpiroz J M, Mosconi E, Bisquert J and De Angelis F 2015 Defect migration in methylammonium lead iodide and its role in perovskite solar cell operation Energy Environ. Sci. 8, 2118

[77] Egger D A, Kronik L and Rappe A M 2015 Theory of Hydrogen Migration in Organic-Inorganic Halide Perovskites Angew. Chem. Int. Ed. 54, 12437-12441

[78] Xiao Z, Yuan Y, Shao Y, Wang Q, Dong Q, Bi C, Sharma P, Gruverman A and Huang J 2015 Giant switchable photovoltaic effect in organometal trihalide perovskite devices Nat. Mater. 14, 193-198

[79] Yuan Y, Chae J, Shao Y, Wang Q, Xiao Z, Centrone A and Huang J 2015 Photovoltaic Switching Mechanism in Lateral Structure Hybrid Perovskite Solar Cells Adv. Energy Mater. 5, 1500615

[80] Eames C, Frost J M, Barnes P R F, O'Regan B C, Walsh A and Islam M S 2015 Ionic transport in hybrid lead iodide perovskite solar cells Nat. Commun. 6, 7497

[81] Yang T-Y, Gregori G, Pellet N, Grätzel M and Maier J 2015 The Significance of Ion Conduction in a Hybrid Organic-Inorganic Lead-Iodide-Based Perovskite Photosensitizer Angew. Chem. Int. Ed. 54, 7905

[82] Yuan Y, Wang Q, Shao Y, Lu H, Li T, Gruverman A and Huang J 2016 Electric-Field-Driven Reversible Conversion Between Methylammonium Lead Triiodide Perovskites and Lead Iodide at Elevated Temperatures Adv. Energy Mater. 6, 1501803

[83] Mosconi E, Meggiolaro D, Snaith H J, Stranks S D and De Angelis F 2016 Light-induced annihilation of Frenkel defects in organo-lead halide perovskites Energy Environ. Sci. 9, 3180- 
3187

[84] Shao Y et al. 2016 Grain boundary dominated ion migration in polycrystalline organic-inorganic halide perovskite films energy environ. Sci. 9, 1752-1759

[85] Yun J S, Seidel J, Kim J, Soufiani A M, Huang S, Lau J, Jeon N J, Seok S I, Green M A and HoBaillie A 2016 Critical Role of Grain Boundaries for Ion Migration in Formamidinium and Methylammonium Lead Halide Perovskite Solar Cells Adv. Energy Mater, DOI: 10.1002/aenm.201600330

[86] Xing J, Wang Q, Dong Q, Yuan Y, Fang Y and Huang J 2016 Ultrafast ion migration in hybrid perovskite polycrystalline thin films under light and suppression in single crystals Phys. Chem. Chem. Phys. 18, 30484-30490

[87] MacDonald G A, Yang M, Berweger S, Killgore J P, Kabos P, Berry J J, Zhu K and DelRio F W 2016 Methylammonium lead iodide grain boundaries exhibit depth-dependent electrical properties Energy Environ. Sci. 9, 3642-3649

[88] Farrington G C and Briant J L 1979 Fast Ionic Transport in Solids Science 204, 1371-1379

[89] Vineyard G H 1957 Frequency factors and isotope effects in solid state rate processes J. Phys. Chem. Solids 3, 121-127

[90] Yu H, Lu H, Xie F, Zhou S and Zhao N 2016 Native Defect-Induced Hysteresis Behavior in Organolead Iodide Perovskite Solar Cells Adv. Funct. Mater. 26, 1411-1419

[91] Haruyama J, Sodeyama K, Han L and Tateyama Y 2015 First-Principles Study of Ion Diffusion in Perovskite Solar Cell Sensitizers J. Am. Chem. Soc. 137, 10048

[92] Bag M, Renna L A, Adhikari R Y, Karak S, Liu F, Lahti P M, Russell T P, Tuominen M T and Venkataraman D 2015 Kinetics of Ion Transport in Perovskite Active Layers and Its Implications for Active Layer Stability J. Am. Chem. Soc. 137, 13130-13137

[93] Baumann A, Väth S, Rieder P, Heiber M C, Tvingstedt K and Dyakonov V 2015 Identification of Trap States in Perovskite Solar Cells J. Phys. Chem. Lett. 6, 2350

[94] Klein-Kedem N, Cahen D and Hodes G 2016 Effects of Light and Electron Beam Irradiation on Halide Perovskites and Their Solar Cells Acc. Chem. Res. 49, 347-354

[95] Jaysankar M, Qiu W, Bastos J, Tait J G, Debucquoy M, Paetzold U W, Cheyns D and Poortmans J 2016 Crystallisation dynamics in wide-bandgap perovskite films J. Mater. Chem. A 4, 10524 10531

[96] Almora O, Zarazua I, Mas-Marza E, Mora-Sero I, Bisquert J and Garcia-Belmonte G 2015 Capacitive Dark Currents, Hysteresis, and Electrode Polarization in Lead Halide Perovskite Solar Cells J. Phys. Chem. Lett. 6, 1645-1652

[97] Brown T M, Friend R H, Millard I S, Lacey D J, Butler T, Burroughes J H and Cacialli F 2003 Electronic line-up in light-emitting diodes with alkali-halide/metal cathodes J. Appl. Phys. 93, 6159

[98] Li C, Credgington D, Ko D-H, Rong Z, Wang J and Greenham N C 2014 Built-in potential shift and Schottky-barrier narrowing in organic solar cells with UV-sensitive electron transport layers. Phys. Chem. Chem. Phys. 16, 12131-12136

[99] Campbell I H, Hagler T W, Smith D I and Ferraris J P 1996 Direct measurement of conjugated polymer electronic excitation energies using metal/polymer/metal structures. Phys. Rev. Lett. 76, 1900

[100] Li C, Beirne G J, Kamita G, Lakhwani G, Wang J and Greenham N C 2014 Probing the switching mechanism in $\mathrm{ZnO}$ nanoparticle memristors J. Appl. Phys. 116, 114501 
[101] Zhang Y et al. 2015 Charge selective contacts, mobile ions and anomalous hysteresis in organicinorganic perovskite solar cells Mater. Horiz. 2, 315-322

[102] Egger D A, Edri E, Cahen D and Hodes G 2015 Perovskite Solar Cells: Do We Know What We Do Not Know? J. Phys. Chem. Lett. 6, 279

[103] Wu B, Fu K, Yantara N, Xing G, Sun S, Sum T C and Mathews N 2015 Charge Accumulation and Hysteresis in Perovskite-Based Solar Cells: An Electro-Optical Analysis Adv. Energy. Mater. 5, 1500829

[104] Nie W, Tsai H, Asadpour R, Neukirch A J, Gupta G, Crochet J J, Chhowalla M, Tretiak S, Alam M A and Wang H-L 2015 High-efficiency solution-processed perovskite solar cells with millimeter-scale grains Science 347, 522-526

[105] Bai Y, Yu H, Zhu Z, Jiang K, Zhang T, Zhao N, Yang S and Yan H 2015 High performance inverted structure perovskite solar cells based on a PCBM:polystyrene blend electron transport layer J. Mater. Chem. A 3, 9098-9102

[106] Kirchartz T, Bisquert J, Mora-Sero I and Garcia-Belmonte G 2015 Classification of solar cells according to mechanisms of charge separation and charge collection Phys. Chem. Chem. Phys. 17, 4007-4014

[107] Choi J et al. 2016 Organolead Halide Perovskites for Low Operating Voltage Multilevel Resistive Switching Adv. Mater. 28, 6562-6567

[108] Gu C and Lee J-S 2016 Flexible Hybrid Organic-Inorganic Perovskite Memory ACS Nano 10, $5413-5418$ 